\title{
PRICING POWER DERIVATIVES: A TWO-FACTOR JUMP-DIFFUSION APPROACH
}

\author{
Pablo Villaplana \\ Universitat Pompeu Fabra \\ Department of Economics and Business \\ Ramon Trias Fargas, 25-27, 08005 Barcelona (Spain) \\ pablo.villaplana@upf.edu
}

\section{Work in Progress}

\begin{abstract}
We propose a two-factor jump-diffusion model with seasonality for the valuation of electricity future contracts. The model we propose is an extension of Schwartz and Smith (Management Science, 2000) long-term / short-term model. One of the main contributions of the paper is the inclusion of a jump component, with a non-constant intensity process (probability of occurrence of jumps), in the short-term factor. We model the stochastic behaviour of the underlying (unobservable) state variables by Affine Diffusions (AD) and Affine Jump Diffusions (AJD). We obtain closed form formulas for the price of futures contracts using the results by Duffie, Pan and Singleton (Econometrica, 2000). We provide empirical evidence on the observed seasonality in risk premium, that has been documented in the PJM market. This paper also complements the results provided by the equilibrium model of Bessembinder and Lemmon (Journal of Finance, 2002), and provides an easy methodology to extract risk-neutral parameters from forward data, that may be used for calibration of real options models.

The model may also be used for scenario generation, valuation of financial options (trough inversion of the characteristic function) and real options applications.
\end{abstract}




\section{PRICING POWER DERIVATIVES: A TWO-FACTOR JUMP- DIFFUSION APPROACH}

\section{INTRODUCTION}

During last years US and EU electricity supply industries are undergoing a process of fundamental change. The main characteristic of this deregulatory process is the creation of a Power Exchange, PX, with an optional or mandatory spot market. In the spot market suppliers and consumers determine market clearing prices and quantities through an auction mechanism. The fact that electricity cannot be stored, makes this commodity a peculiar one. Market-clearing prices are volatile and they are subject to upward and temporary spikes. As a consequence, a market for financial instruments has been usually created to allow the participants to hedge price risk, through a set of financial instruments (futures, forwards, options...).

The main goal of this paper is to provide a model for the valuation of futures contracts, and a better understanding of the compensation agents in power markets require to bear price risk. Our proposed models are expressed in reduced-form and extend previous work by Schwartz and Smith ${ }^{1}$ (2000), Lucia and Schwartz (2002) and Deng (2001), we also take into account in the specification of the state variables the results obtained by Pirrong and Jermakyan (2000), Bessembinder and Lemmon (2002) and Escribano, Peña and Villaplana (2002) among others.

We propose two different sets of two-factor jump-diffusion models with seasonality for the valuation of electricity derivative contracts depending if we analyse spot price or log-spot price. Both price and log-price models are two-factor jump-diffusion models. The models we propose are extensions of Schwartz and Smith (2000) and Lucia and Schwartz (2002), and both of them are special cases of some of the models we propose. The major extension is the inclusion of a jump component in the short-term factor, also allowing the intensity process (probability of occurrence of jumps) to be non-constant. This major extension follows the suggestions proposed by Schwartz and Smith (2000), Lucia and Schwartz (2002) and the results provided by, among others, Escribano et al. (2002). We have analysed two different types of jump components (Gaussian or Exponential jump size distribution). We also extend the specification for the long-term factor (equilibrium level), and specify the long-term factor either as an Arithmetic

\footnotetext{
${ }^{1}$ Schwartz and Smith (2000) develops a two-factor model of commodity prices that allows meanreversion in short-term prices and uncertainty in the equilibrium model to which prices revert.
} 
Brownian Motion (like in the original work of Schwartz and Smith, 2000) or a MeanReverting Process. Therefore, for each subset of models (spot price or log-spot price) we have four different models that are the result of combining the two different specifications for the jump component and the two different specifications for the longterm factor.

We model the stochastic behaviour of the underlying (unobservable) state variables by Affine Diffusions (AD) and Affine Jump Diffusions (AJD). With these specifications we are able to exploit the recent transform analysis of Duffie, Pan and Singleton (2000), and Chacko and Das (2002) and we obtain closed form formulas, for the price of futures contracts and options (trough inversion of the characteristic function, that is obtained in closed-form).

One of the main goals of financial markets in general, and futures markets in particular is to facilitate the transfer of risk to those willing to bear it. The forward premium (defined as the difference between the current futures price and the expected price on the delivery date) represents the compensation required in equilibrium by those who support the price risk of the underlying commodity. The sign and size of the forward premium should be, therefore, related to economic risks and the willingness of different market participants to bear these risks (Hirshleifer,1990; Longstaff and Wang, 2002). Given the relative importance of spikes in electricity prices (see for example Knittel and Roberts, 2001; Escribano et al., 2002; Geman and Roncoroni, 2003), different types of price risk seems to be at work in electricity forward contracts. Previous empirical evidence (at least for the PJM market) has provided evidence on the existence of an important risk premium with seasonal behavior (with significant differences in both size and sign), see Pirrong and Jermakyan (2000). Bessembinder and Lemmon (2002) present an equilibrium model and show the differences in SIZE and SIGN may exist in electricity markets (depending on the degree of skewness of electricity prices), see also Geman and Vasicek (2001).

Some work has already been done on the valuation of electricity forward contracts. Lucia and Schwartz (2002) examine the importance of the regular pattern in the behavior of electricity prices and its implications for valuation of forward contracts. They analyse one and two-factor diffusion models, extending the long-term short-term model of Schwartz and Smith (2000) by incorporating seasonality (deterministic function) and applying the analysis to NordPool futures and forwards data. On the other hand, Pirrong and Jermakyan (2000), Bessembinder and Lemmon (2002) and Longstaff 
and Wang (2002) among others, deal with the valuation of forward contracts in the Pennsylvania- New jersey - Maryland market (PJM henceforth). Their findings show that electricity forward prices contain an important risk premium, that is, forward prices (expected spot price at maturity under the risk-neutral measure) differ from expected delivery date spot prices (under the objective probability function). Pirrong and Jermakyan (2000) (PJ henceforth) consider the difference as an endogenous market price of power demand risk. Bessembinder and Lemmon (2002) (BL henceforth) present an equilibrium model (with limited participation), their model predicts "forward power price is a downward biased predictor of the future spot price (negative forward premium) if expected power demand is low and demand risk is moderate. However, the equilibrium forward premium increases when either expected demand or demand variance is high, because the positive skewness in the spot power price distribution". The empirical evidence (for the PJM market) provided by BL and PJ indicates the premium in forward markets is positive and greatest during summer months ${ }^{2}$, and negative or zero in the rest of the months. We will show this seasonal pattern in the risk premium can be captured by our model and may be interpreted as a jump risk premium related to the observed (under the objective probability measure) seasonal pattern of spikes in the PJM market (see also Escribano et al. (2002)). Lucia and Schwartz (2002) showed the pattern, size and sign of forward risk premium in NordPool is not clear. In fact, even the sign of the market forward premium in NordPool is not clear. Their results for the one-factor model show the market price of risk is positive, so that the forward premium is negative, while in the results for the two-factor model the market price of risk is negative (for both the short and the long-term factor), so that the forward premium is positive (forward price larger than expected spot price at the delivery date, under the objective probability measure). However, their "quantitative" results should be considered as preliminary. The fact that, as Escribano et al.(2002) showed, jumps are comparatively less important in NordPool than in the PJM market may lie behind the differences in forward risk premium behavior. Lucia and Schwartz (2002) consider as an interesting line of research the inclusion of jumps and/or the possibility of seasonal risk premium. Here we follow this idea and show the existence of "seasonal skewness" under the objective probability measure, that may translate into "seasonal forward premium". It also must be noted, by introducing the jump component we are able to

\footnotetext{
${ }^{2}$ In the PJM market demand is higher during summer months, and prices are also more volatile with spikes. See Escribano et al. (2002) for the seasonal behavior of spikes in this market.
} 
distinguish between short-term (and long-term) risk premiums and jump risk premium. It seems plausible that agents react in different ways to different types of uncertainty. Our specification is therefore more flexible than Schwartz and Smith (2000) and Lucia and Schwartz (2002), since we allow forward risk premium to be composed by different kinds of risk premium.

While PJ and BL provide empirical evidence and theoretical arguments for the existence and sign of a forward premium in electricity markets in general (and in particular in the PJM market) their practical implications for the valuation of derivatives contracts are limited. We provide a model that can be used for the valuation of derivatives contracts and is able to capture the salient features of forward curve in the PJM as documented by PJ, BL and Longstaff and $\mathrm{Wang}^{3}$ (2002). That is our specification captures the seasonality in jumps (see Escribano et al., 2002) and in risk premiums (see Bessembinder and Lemmon (2002) and Pirrong and Jermakyan (2000)).

For the NordPool market, we show the existence of a (seasonal) jump component under the objective probability measure (as has been already documented in Escribano et al. (2002)) and provide a model for forward valuation that allows for such component and therefore allows seasonal behavior of the risk premium. It must be noted, that seasonality in jumps in NordPool is smoother than in PJM and relatively less important. Since on one hand, there exist jumps in electricity prices in the NordPool and on the other hand Lucia and Schwartz (2002) is a special case of our model, it seems plausible our model should provide smaller valuation errors than theirs.

The paper is organized as follows. Section 2 presents the mathematical preliminaries that allow us to derive closed-form formulas for the price of futures contracts when the underlying follows a jump-diffusion process. This section follows the presentation of Duffie, Pan and Singleton (2000). Section 3 presents the specification of the state variables under the objective probability measure. In Section 4 we present the specification under the risk-neutral measure and provide the price formulas for all the eight models we consider in this paper. Model's calibration and empirical behavior of forward curves is provided in Section 5. Last section concludes and provides lines for future research.

\footnotetext{
${ }^{3}$ Our model and our preliminary results also support the hypothesis analysed by Longstaff and Wang (2002) that "electricity forward prices are determined rationally by risk-averse economic agents".
} 


\section{MATHEMATICAL PRELIMINARIES}

The existence of spikes in deregulated electricity markets in almost all the countries that have created a PX (see Escribano et al., 2002), points out the importance of introducing jumps in a model for the pricing of contingent claims. That is, in order to obtain reliable estimates for the prices of contingent claims, we must move away from the diffusion assumption and we have to model the underlying state vector with a jump-diffusion process. An assumption that has been proved very useful in the finance literature is that the state vector $X$ follows an affine jump-diffusion process (AJD). An AJD is a jumpdiffusion process for which drift vector, "instantaneous" covariance matrix, and jump intensities all have an affine (linear) dependence on the state vector. The affine jumpdiffusion processes have been recently synthesized and extended by Duffie, Pan and Singleton (2000) (DPS henceforth), see also Chacko and Das (2002). Affine diffusions (AD) and affine jump-Diffusion (AJD) are quite useful in modelling underlying state variable for several reasons. DPS have shown the close connection between the structure of this kind of models and some transforms (Fourier), and how from this transform we can obtain derivative prices ${ }^{4}$. We propose two two-factor model with jumps to model the underlying evolution of electricity spot prices in deregulated markets.

\section{1.- Affine and Affine Jump- Diffusions Processes}

We model the evolution of the underlying state variables with a general class of continuous time stochastic processes, the so-called affine jump-diffusion (AJD) processes. We follow here the presentation in Duffie, Pan and Singleton (2000), see also Chacko and Das (2002). Fix a probability space $\{\Omega, F, P\}$ and an information filtration $\left(F_{t}\right)=\left\{F_{t}: \mathrm{t} \geq 0\right\}$, and suppose that $X_{t}$ is a Markov process in some state space $D \in \mathfrak{R}^{n}$, following the stochastic differential equation (SDE):

$d X_{t}=\mu\left(X_{t}\right) d t+\sigma\left(X_{t}\right) d W_{t}+J d N(\lambda)$

where $W_{t}$ is an $\left(F_{t}\right)$-standard Brownian Motion in $\mathfrak{K}^{n}, \boldsymbol{\mu}(\cdot): D \rightarrow \mathfrak{R}^{n}$ and $\sigma(\cdot): D \rightarrow \mathfrak{K}^{n}$ are respectively the drift and diffusion functions, and $J d N(\lambda)$ is a pure jump process with intensity $\left\{\lambda\left(X_{t}\right): t \geq 0\right\}$, and jump amplitude distribution $J$ on $\mathfrak{\Re}^{n}$. Intuitively, $\mu(\cdot)$ and $\sigma(\cdot)$ are the drift and diffusion term of the process when no jump occurs, and the jump term captures the discontinuous change of the path with both random arrival of

\footnotetext{
${ }^{4}$ Heston (1993) introduced the use of Fourier Transforms in derivative pricing. He showed call option pricing formulas can be computed by Fourier inversion of the conditional characteristic function, which has a closed-form for his particular affine stochastic volatility model.
} 
jumps and random jump sizes. That is, conditional on the path of $\mathrm{X}$, the jump times of the jump term are the jumps times of a Poisson process with, possibly, time-varying intensity $\left\{\lambda\left(X_{s}\right): 0 \leq s \leq t\right\}$, and the size of the jump of at a jump time s' is independent of $\left\{\mathrm{X}_{\mathrm{s}}: 0 \leq \mathrm{s} \leq \mathrm{s}^{\prime}\right\}$ and has the probability distribution $\mathrm{J}$.

Following Duffie, Pan and Singleton (2000) we impose an "affine" structure on the coefficients functions $\mu, \sigma \sigma^{\prime}$ and $\lambda$. Following DPS presentation, we have:

$$
\begin{gathered}
\mu(x)=K_{0}+K_{l} \cdot x \\
\left(\sigma(x) \sigma(x)^{\prime}\right)_{i j}=\left(H_{0}\right)_{i j}+\left(H_{l}\right)_{i j} \cdot x \\
\lambda(x)=l_{0}+l_{l} \cdot x \\
R(x)=\rho_{0}+\rho_{l} \cdot x
\end{gathered}
$$

Where $K=\left\{K_{0}, K_{l}\right\} \in \mathfrak{R}^{\mathrm{n}} \times \mathfrak{R}^{\mathrm{n} \times \mathrm{n}}, H=\left\{H_{0}, H_{l}\right\} \in \mathfrak{R}^{\mathrm{n}} \times \mathfrak{R}^{\mathrm{n} \times \mathrm{n} \times \mathrm{n}}, l=\left\{l_{0}, l_{l}\right\} \in \mathfrak{R} \times \mathfrak{R}^{\mathrm{n}}, \rho=$ $\left(\rho_{0}, \rho_{l}\right) \in \mathfrak{R} \times \mathfrak{R}^{\mathrm{n}}$. Let $\Theta(c)=\int_{\mathfrak{R}}{ }^{\mathrm{n}} \exp \{c \cdot z\} \operatorname{dv}(\mathrm{z})$, be the jump transform of the jump size distribution ${ }^{5}$. The function $\theta(\bullet)$ completely determines the jump size distribution. We assume constant interest rates $\left(\rho_{l}=0\right.$ in equation $\left.(1 \mathrm{~d})\right)$, and therefore futures prices are equal to forward prices. Let $\vartheta \equiv(K, H, l, \theta, \rho)$, it captures both the distribution of the vector process $X$ as well as the effects of discounting and determines a transform ${ }^{6} \Psi^{\vartheta}$ : $\mathrm{C}^{\mathrm{n}} \times \mathrm{D} \times \mathfrak{R}_{+} \times \mathfrak{R}_{+} \rightarrow \mathrm{C}$ of $\mathrm{X}_{\mathrm{T}}$ conditional on corresponding filtration at $\mathrm{t} F_{t}, \mathrm{t} \leq \mathrm{T}$, by

$$
\Psi^{\vartheta}(u, X, t, T) \equiv E^{\vartheta}\left[\exp \left(-\int_{t}^{T} R\left(X_{s}\right) d s\right) \cdot e^{u X_{T}} \mid F_{t}\right]
$$

where $E^{\vartheta}$ denotes expectation operator under the distribution of $X$ determined by $\vartheta$. Note that the difference between $\Psi^{\vartheta}$ and the conditional characteristic function of the distribution of $X_{T}$ is the discounting factor.

Duffie, Pan and Singleton (2000) prove that the affine structure in (1) implies, under technical regularity conditions, $\boldsymbol{\Psi}(\bullet)$ has the exponential-affine form:

$$
\Psi^{\vartheta}(u, x, t, T) \equiv e^{\alpha(u, t, T)+\beta(u, t, T) x}
$$

\footnotetext{
${ }^{5}$ Let $\mathrm{v}$ be the jump size distribution and let $\mathrm{g}(\mathrm{z})$ be the corresponding density function, then, $\theta \equiv \int \exp (\mathrm{cz})$ $d v(z)=\int \exp (c z) g(z) d z$. Therefore, $\theta$ is the characteristic function of the jump size distribution. Since we are going to deal either with normally or exponential distributed jump sizes, $\theta$ will be the characteristic function of Gaussian or Exponential distribution, depending of the assumptions of a particular model. ${ }^{6}$ In the general setting of DPS, $u$ is an $\mathrm{n}$-dimensional vector, belonging to the set of complex numbers. Along this paper is enough to consider $u$ is a vector of real numbers. In fact, along all this paper, $u$ will be at most a two-dimensional vector, with 1 or zero in its components.
} 
where $\alpha$ and $\beta$ satisfy the complex-valued Riccati equations:

$$
\begin{aligned}
& \dot{\alpha}(t)=\rho_{0}-K_{0}^{T} \beta(t)-\frac{1}{2} \beta(t)^{T} H_{0} \beta(t)-l_{0}(\theta(\beta(t))-1) \\
& \dot{\beta}(t)=\rho_{1}-K_{1}^{T} \beta(t)-\frac{1}{2} \beta(t)^{T} H_{1} \beta(t)-l_{1}(\theta(\beta(t))-1)
\end{aligned}
$$

with boundary conditions, $\beta(T)=u, \alpha(T)=0$.

For the log-spot price models we show futures price formula is completely determined by $\boldsymbol{\Psi}(u, X, t, T)$ with $u=(1,1)$, (see Appendix A). However for price-level models we have to calculate a simplified version ${ }^{7}$ of the "extended" transform. Again, following DPS we define the "extended" transform $\boldsymbol{\Phi}^{\vartheta}: \mathfrak{R}^{\mathrm{n}} \times \mathrm{C}^{\mathrm{n}} \times \mathrm{D} \times \mathfrak{R}_{+} \times \mathfrak{R}_{+} \rightarrow \mathrm{C}$ of $\mathrm{X}_{\mathrm{T}}$ conditional on corresponding filtration at $\mathrm{t} F_{t}, \mathrm{t} \leq \mathrm{T}$, by

$$
\Phi^{\vartheta}(v, u, X, t, T)=E\left(\exp \left(-\int_{t}^{T} R\left(X_{s}\right) d s\right)\left(v \cdot X_{T}\right) e^{u \cdot X_{T}} \mid F_{t}\right)
$$

Again, under technical conditions, including the differentiability of the jump transform $\theta$, it may be shown:

$$
\Phi^{\vartheta}(v, u, x, t, T)=\Psi^{\vartheta}(u, x, t, T) \cdot(A(t)+B(t) \cdot x)
$$

where $\Psi^{\vartheta}$ is given by expression (3) and where $A$ and $B$ satisfy the linear ordinary differential equations:

$$
\begin{aligned}
& -\dot{B}(t)=K_{1}^{T} B(t)+\boldsymbol{\beta}(t)^{T} H_{1} B(t)+l_{1} \nabla \boldsymbol{\theta}(\boldsymbol{\beta}(t)) B(t) \\
& -\dot{A}(t)=K_{0} B(t)+\boldsymbol{\beta}(t)^{T} H_{0} B(t)+l_{0} \nabla \boldsymbol{\theta}(\boldsymbol{\beta}(t)) B(t)
\end{aligned}
$$

with the boundary conditions $\mathrm{B}(\mathrm{T})=v$ and $\mathrm{A}(\mathrm{T})=0$, and where $\nabla \theta(\mathrm{c})$ is gradient of $\theta(c)$ with respect to $c \in C^{n}$. We show in Appendix A (see equation A.1 and A.2) the close connection between the expressions (3) and (6) and the futures price formula for log-price and level price models.

\section{SPECIFICATION OF STATE VARIABLES UNDER THE OBJECTIVE PROBABILITY MEASURE}

We have two different sets of models depending if we analyse spot price or logspot price. Traditionally, commodity price models have been stated in terms of log-

\footnotetext{
${ }^{7}$ In our applications the calculation of the extended transform will simplify since we will work with $v=$ $(1,1)$ and $u=(0,0)$
} 
prices (see e.g. Schwartz, 1997 and Schwartz and Smith, 2000), although we consider in the case of electricity prices, and because the existence of jumps, models for the valuation of electricity derivatives should be stated in price levels. The reason is logtransformation affects the estimation of the jump component, in particular on those markets where jumps are relatively less important, logarithmic transformation may affect the estimation of the jump component. In particular, the log-transformation affect the skewness of the series (that in our model is controlled by the jump component). The empirical evidence presented by Lucia and Schwartz (2002) and by Escribano et al. (2002) also seems to favour price-level specification. In particular, Lucia and Schwartz (2002) found their price models fitted forward prices better than log-price models. Moreover, as has been pointed out by Bessembinder and Lemmon (2002) and Pirrong and Jermakyan (2000), the huge risk premium observed in summer months in PJM is closely related to "skewness" premium (i.e. "jump" risk premium). Therefore it may be the case, that in some markets log-prices are less skewed and the existence of skewness seasonality (or jump seasonality) exists in the price level series but is difficult to estimate empirically (under the objective probability measure) if the analyst uses logprice series. In any case, we present both sets of models and derive the futures price formula for the spot price and the log-price case. However, we emphasize the use of price models, and in the empirical section we will show spot price models represent in a better way the characteristics of the market. We will also show, the qualitative behavior of forward contracts under log-price or price models is not too different.

All of the specifications include a deterministic factor (sinusoidal function) that tries to capture the observed seasonality in electricity spot and futures prices. Both spot price and log-spot price models are two-factor jump-diffusion models. As we stated before, the two factors resemble partially the model proposed by Schwartz and Smith (2000). The major difference is that in our models, the mean-reverting (or short-term process) is allowed to jump (with non-constant intensity process). We have analysed two different types of jump components (Gaussian or Exponential jump size distribution). Another extension is to allow two different specifications for the long-term factor (Arithmetic Brownian Motion or Mean-Reverting Process).

For each subset of models (spot price or log-spot price) we have four different models that are the result of combining the two different specifications for the jump component and the two different specifications for the long-term factor, so we are dealing with 
eight different models. Therefore the models we propose differ among them by three characteristics:

a) Relevant variable: Price Level vs. Log-Price

b) Jump Size distribution: Gaussian vs. Exponential Jumps

c) Long-term factor: Arithmetic Brownian Motion vs. Mean Reverting process

Table 1 and 2 summarizes the models we analyse.

Table 1: Summary of the specifications of relevant state variables.

\begin{tabular}{|c|c|c|c|c|}
\hline Price / Log-Price & Model 1 $^{\mathbf{a}}$ & Model 1b & Model 2a & Model 2b \\
\hline $\begin{array}{l}\text { Short-term factor }(\boldsymbol{\chi}) \\
\text { with } \\
\text { Jump component: } \\
\text { seasonal intensity process } \\
\text { size distrib.: Gauss./Exp. }\end{array}$ & $\begin{array}{c}\text { Ornstein- } \\
\text { Uhlenbeck } \\
+ \\
\text { Gaussian } \\
\text { Jump Size }\end{array}$ & $\begin{array}{l}\text { Ornstein- } \\
\text { Uhlenbeck } \\
\quad+ \\
\text { Exponential } \\
\text { Jump Size }\end{array}$ & $\begin{array}{c}\text { Ornstein- } \\
\text { Uhlenbeck } \\
\qquad+ \\
\text { Gaussian } \\
\text { Jump Size }\end{array}$ & $\begin{array}{l}\text { Ornstein- } \\
\text { Uhlenbeck } \\
+ \\
\text { Exponential } \\
\text { Jump Size }\end{array}$ \\
\hline $\begin{array}{c}\text { Long-term factor } \\
\text { (equilibrium level) : } \xi\end{array}$ & $\begin{array}{l}\text { Arithmetic } \\
\text { Brownian } \\
\text { Motion }\end{array}$ & $\begin{array}{l}\text { Arithmetic } \\
\text { Brownian } \\
\text { Motion }\end{array}$ & $\begin{array}{l}\text { Ornstein- } \\
\text { Uhlenbeck }\end{array}$ & $\begin{array}{l}\text { Ornstein- } \\
\text { Uhlenbeck }\end{array}$ \\
\hline
\end{tabular}

The first two models (Model 1a and Model 1b) resemble those proposed by Schwartz and Smith (2000) and Lucia and Schwartz (2002), without jumps. In both papers the first factor captures short-term movements and is modelled with an Ornstein-Uhlenbeck (OU) process while the second factor (long-term equilibrium) is modelled with an Arithmetic Brownian Motion (ABM). One of the main contributions of this paper is to introduce jumps in the short-term deviations factor $\chi$. We analyze two different specifications for the jump component and allow the intensity process to be nonconstant. We take into account two different specifications, in Model 1a and 2a we assume jump size distribution is Gaussian while in Model $1 b$ and $2 b$ we allow for two type of jumps (see also, Deng (2001)), each with exponential distributed jump magnitude. The Gaussian assumption imposes symmetry in the jump distribution while the exponential assumption allows for asymmetry and separates positive and negative jumps. Schwartz and Smith (2000) state the inclusion of jumps as a possible extension in order to deal with electricity prices but, to the best of our knowledge, no one has still 
pursued this line of research. This general model takes into account short term deviations from equilibrium prices $(\chi)$ and also big and short lived departures from it in form of jumps. At the same time since deregulation of electricity markets is recent, there could exist some uncertainty on the level of equilibrium prices (threat of new entrants, possibility of horizontal and vertical disintegration, regulatory risk,...) that is captured by allowing the equilibrium level to be stochastic. Schwartz and Smith (2000) originally assume long-term equilibrium follows ${ }^{8}$ an Arithmetic Brownian Motion (ABM). This assumption introduces a (positive or negative) trend in the futures price formula (see Table 3 and 4). We have introduced an alternative possible assumption, mean-reverting long-term factor ${ }^{9}$. This specification may be more interesting than the ABM, originally proposed by Schwartz and Smith (2000) and used by Lucia and Schwartz (2002). While the $\mathrm{ABM}$ specification introduces a deterministic time trend in the futures formula (both in the price level and log-price subsets of models), a mean-reverting equilibrium level may be more useful to capture transient (although long lasting) increases or decreases of the equilibrium level, that ultimately would revert to an average equilibrium level. For instance, in a system mainly driven by hydro resources, during years of low water reservoirs the equilibrium level could increase temporarily during few years because the change in the cost structure in the supply side. With the MR equilibrium level specification we do not force equilibrium level to increase or decrease systematically with time but allow equilibrium levels to be different during several years, if there exist some temporary change in the cost structure of the market, for instance because temporary smaller generation capacity. Which specification (ABM or MR) is the most adequate for each market requires an empirical answer.

Although the inclusion of a long-term process may be interesting for some applications that need to take into account the long-run behavior of electricity prices (for instance real options valuation), it must be noted the long-term factor (independently of the specification we use) will not play a substantial role in the valuation of futures contracts, which usually have a maturity no longer than one year. As BL pointed out (and showed empirically at least for the PJM market) risk premium in forward contracts is due to the skewness (governed in our model by the jump component) of electricity

\footnotetext{
${ }^{8}$ It should be noted, Schwartz and Smith (2000) dealt with oil forward contracts, and therefore the assumption for the long-term factor may be different depending the commodity we analyze.

${ }^{9}$ Mean-reverting equilibrium models have been used in the interest rate literature by Balduzzi et al. (1996, 1998, 2000) and Jegadeesh and Pennacchi (1996), in models with a "stochastic central tendency".
} 
price distribution at maturity. (It can be shown skewness of the distribution is mainly governed by the jump component, for instance by derivation of the characteristic function, that may be calculated using the ODE approach outlined in previous section). 
Table 2: Summary of theoretical models under the objective probability measure.

\begin{tabular}{|c|c|c|}
\hline Model & \begin{tabular}{|l|} 
Price Level Specification \\
\end{tabular} & Log-Price Specification \\
\hline $\begin{array}{l}\text { Short-term: MR } \\
\text { Long-term: ABM } \\
\text { Jump: Gaussian }\end{array}$ & $\begin{array}{l}S_{t}=f(t)+\chi_{t}+\xi_{t} \\
d \chi_{t}=-k \chi_{t} d t+\sigma_{\chi} d Z_{\chi}+J\left(\mu_{J}, \sigma_{J}^{2}\right) d \Pi\left(\lambda_{t}\right) \\
d \xi=\mu_{\xi} d t+\sigma_{\xi} d Z_{\xi} \\
d Z_{\chi} d Z_{\xi}=\rho d t\end{array}$ & $\begin{array}{l}\ln S_{t}=f(t)+\chi_{t}+\xi_{t} \\
d \chi_{t}=-k \chi_{t} d t+\sigma_{\chi} d Z_{\chi}+J\left(\mu_{J}, \sigma_{J}^{2}\right) d \Pi\left(\lambda_{t}\right) \\
d \xi=\mu_{\xi} d t+\sigma_{\xi} d Z_{\xi} \\
d Z_{\chi} d Z_{\xi}=\rho d t\end{array}$ \\
\hline $\begin{array}{l}\text { Short-term factor: MR } \\
\text { Long-term factor: MR } \\
\text { Jump: Gaussian }\end{array}$ & $\begin{array}{l}S_{t}=f(t)+\chi_{t}+\xi_{t} \\
d \chi_{t}=-k \chi_{t} d t+\sigma_{\chi} d Z_{\chi}+J\left(\mu_{J}, \sigma_{J}^{2}\right) d \Pi\left(\lambda_{t}\right) \\
d \xi=k_{\xi}(\xi-\xi) d t+\sigma_{\xi} d Z_{\xi} \\
d Z_{\chi} d Z_{\xi}=\rho d t\end{array}$ & $\begin{array}{l}\ln S_{t}=f(t)+\chi_{t}+\xi_{t} \\
d \chi_{t}=-k \chi_{t} d t+\sigma_{\chi} d Z_{\chi}+J\left(\mu_{J}, \sigma_{J}^{2}\right) d \Pi\left(\lambda_{t}\right) \\
d \xi=k_{\xi}(\xi-\xi) d t+\sigma_{\xi} d Z_{\xi} \\
d Z_{\chi} d Z_{\xi}=\rho d t\end{array}$ \\
\hline $\begin{array}{l}\text { Short-term factor: MR } \\
\text { Long-term factor: ABM } \\
\text { Jump: Exponential }\end{array}$ & $\begin{array}{l}S_{t}=f(t)+\chi_{t}+\xi_{t} \\
d \chi_{t}=-k_{\chi} \chi_{t} d t+\sigma_{\chi} d Z_{\chi}+J_{u}\left(\eta_{t}\right) d N\left(\lambda_{t, u}\right)-J_{d}\left(\eta_{d}\right) d N\left(\lambda_{t, d}\right) \\
d \xi=\mu_{\xi} d t+\sigma_{\xi} d Z_{\xi} \\
d Z_{\chi} d Z_{\xi}=\rho d t\end{array}$ & $\begin{array}{l}\ln S_{t}=f(t)+\chi_{t}+\xi_{t} \\
d \chi_{t}=-k_{\chi} \chi_{t} d t+\sigma_{\chi} d Z_{\chi}+J_{u}\left(\eta_{u}\right) d N\left(\lambda_{t, u}\right)-J_{d}\left(\eta_{d}\right) d N\left(\lambda_{t, d}\right) \\
d \xi=\mu_{\xi} d t+\sigma_{\xi} d Z_{\xi} \\
d Z_{\chi} d Z_{\xi}=\rho d t\end{array}$ \\
\hline $\begin{array}{l}\text { Short-term factor: MR } \\
\text { Long-term factor: MR } \\
\text { Jump: Exponential }\end{array}$ & $\begin{array}{l}S_{t}=f(t)+\chi_{t}+\xi_{t} \\
d \chi_{t}=-k_{\chi} \chi_{t} d t+\sigma_{\chi} d Z_{\chi}+J_{u}\left(\eta_{u}\right) d N\left(\lambda_{t, u}\right)-J_{d}\left(\eta_{d}\right) d N\left(\lambda_{t, d}\right) \\
d \xi=k_{\xi}(\xi-\xi) d t+\sigma_{\xi} d Z_{\xi} \\
d Z_{\chi} d Z_{\xi}=\rho d t\end{array}$ & $\begin{array}{l}\ln S_{t}=f(t)+\chi_{t}+\xi_{t} \\
d \chi_{t}=-k_{\chi} \chi_{t} d t+\sigma_{\chi} d Z_{\chi}+J_{u}\left(\eta_{u}\right) d N\left(\lambda_{t, u}\right)-J_{d}\left(\eta_{d}\right) d N\left(\lambda_{t, d}\right) \\
d \xi=k_{\xi}(\xi-\xi) d t+\sigma_{\xi} d Z_{\xi} \\
d Z_{\chi} d Z_{\xi}=\rho d t\end{array}$ \\
\hline
\end{tabular}




\section{RISK NEUTRAL PROCESSES AND VALUATION}

In all the models we have proposed there are four sources of uncertainty, those generated by the diffusive factors (short term uncertainty and long term uncertainty) and two sources of uncertainty generated by the jump component. Jump risk is composed by jump-intensity risk and by jump-size risk. The risk-neutral ${ }^{10}$ parameters are therefore $\left(\phi_{\chi}, \phi_{\xi}, \lambda^{*}, \mu_{J}^{*}\right)$. The lack of liquidity in electricity forward contracts imply the observable forward contracts are those with the shortest maturities. Therefore, at this stage of development of electricity forward and futures markets, the most important risk components for the valuation of forward contracts would be the short-term risk premia and the jump risk premia.

If we focus on the market prices of jump risks, we may allow the risk-neutral mean jump size $\mu_{J}^{*}$ to be different from its data-generating counterpart $\mu_{J}$, therefore we are incorporating a premium for jump-size uncertainty. On the other hand, we may incorporate a premium for jump-timing risk, if we allow the parameter $\lambda_{t}^{*}$ for the riskneutral jump-arrival intensity to be different from its data-generating counterpart $\lambda_{t}$. Therefore, differences between $\mu_{J}$ and $\mu_{J}^{*}$ and between $\lambda_{t}$ and $\lambda_{t}{ }^{*}$, will be a measure of market risk premium for each source of jump uncertainty. We make the simplifying assumption (see also Pan, 2002) that all the risk premia is captured by jump-size risk, therefore we assume $\lambda_{t}^{*}=\lambda_{t}$.

Once we have specified the models under the risk-neutral measure we have to apply the transform analysis to obtain electricity futures prices. Table 3 and 4 provide the riskneutral specifications and futures price formulas for price level and log-price models. We present some detailed derivation for the pricing formulas in the Appendix.

\footnotetext{
${ }^{10}$ Under the objective probability distribution, $\phi_{\ell}=\phi_{\xi}=0$, the intensity process (probability of jumps) is given by $\lambda_{\varphi}$ and the mean jump size is $\mu_{\text {. }}$.
} 
Table 3: Summary of theoretical models and formulas. Price level specification.

\begin{tabular}{|c|c|c|}
\hline Model & Risk-neutral specification & Futures Price Formula \\
\hline $\begin{array}{l}\text { Short-term: MR } \\
\text { Long-term: ABM } \\
\text { Jump: Gaussian }\end{array}$ & $\begin{array}{l}S_{t}=f(t)+\chi_{t}+\xi_{t} \\
d \chi_{t}=-\left(k \chi_{t}+\phi_{\chi}\right) d t+\sigma_{\chi} d Z_{\chi}^{*}+J\left(\mu_{J}^{*}, \sigma_{J}^{2}\right) d \Pi\left(\lambda_{t}^{*}\right) \\
d \xi=\left(\mu_{\xi}-\phi_{\xi}\right) d t+\sigma_{\xi} d Z_{\xi}^{*} \\
d Z_{\chi}^{*} d Z_{\xi}^{*}=\rho d t\end{array}$ & $\begin{array}{l}F\left(t, T, S_{t}\right)=f(T)+\left(\mu_{\xi}-\phi_{\xi}\right) \tau-\frac{\phi_{\chi}}{k}\left(1-e^{-k_{\chi} \tau}\right) \\
+e^{-k_{\chi} \tau} \chi_{t}+\xi_{t}+\lambda(t, T) \frac{\mu_{J}^{*}}{k}\left(1-e^{-k_{\chi} \tau}\right)\end{array}$ \\
\hline $\begin{array}{l}\text { Short-term factor: MR } \\
\text { Long-term factor: MR } \\
\text { Jump: Gaussian }\end{array}$ & $\begin{array}{l}S_{t}=f(t)+\chi_{t}+\xi_{t} \\
d \chi_{t}=-\left(k \chi_{t}+\phi_{\chi}\right) d t+\sigma_{\chi} d Z_{\chi}^{*}+J\left(\mu_{J}^{*}, \sigma_{J}^{2}\right) d \Pi\left(\lambda_{t}^{*}\right) \\
d \xi=k_{\xi}\left(\xi^{*}-\xi\right) d t+\sigma_{\xi} d Z_{\xi}^{*} \\
d Z_{\chi}^{*} d Z_{\xi}^{*}=\rho d t\end{array}$ & $\begin{array}{l}F\left(t, T, S_{t}\right)=f(T)+\xi^{*}\left(1-e^{-k_{\xi} \tau}\right)-\frac{\phi_{\chi}}{k}\left(1-e^{-k_{\chi} \tau}\right) \\
+e^{-k_{\chi} \tau} \chi_{t}+e^{-k_{\xi} \tau} \xi_{t}+\lambda(t, T) \frac{\mu_{J}^{*}}{k}\left(1-e^{-k_{\chi} \tau}\right)\end{array}$ \\
\hline $\begin{array}{l}\text { Short-term factor: MR } \\
\text { Long-term factor: ABM } \\
\text { Jump: Exponential }\end{array}$ & $\begin{array}{l}S_{t}=f(t)+\chi_{t}+\xi_{t} \\
d \chi_{t}=-\left(k_{\chi} \chi_{t}+\phi_{\chi}\right) d t+\sigma_{\chi} d Z_{\chi}^{*}+J_{u}^{*}\left(\eta_{u}^{*}\right) d N\left(\lambda_{t, u}^{*}\right)-J_{d}^{*}\left(\eta_{d}^{*}\right) d N\left(\lambda_{t, d}^{*}\right) \\
d \xi=\left(\mu_{\xi}-\phi_{\xi}\right) d t+\sigma_{\xi} d Z_{\xi}^{*} \\
d Z_{\chi}^{*} d Z_{\xi}^{*}=\rho d t\end{array}$ & $\begin{array}{l}F\left(t, T, S_{t}\right)=f(T)+\left(\mu_{\xi}-\phi_{\xi}\right) \tau-\frac{\phi_{\chi}}{k_{\chi}}\left(1-e^{-k_{\chi} \tau}\right) \\
+e^{-k_{\chi} \tau} \chi_{t}+\xi_{t}+\sum_{i=\text { up }, \text { down }} \lambda_{i, T}\left(1-e^{-k \tau}\right)_{i}^{*}\end{array}$ \\
\hline $\begin{array}{l}\text { Short-term factor: MR } \\
\text { Long-term factor: MR } \\
\text { Jump: Exponential }\end{array}$ & $\begin{array}{l}S_{t}=f(t)+\chi_{t}+\xi_{t} \\
d \chi_{t}=\left(-k \chi_{t}+\phi_{\chi}\right) d t+\sigma_{\chi} d Z_{\chi}^{*}+J_{u}^{*}\left(\eta_{u}^{*}\right) d N\left(\lambda_{t, u}^{*}\right)-J_{d}^{*}\left(\eta_{l}^{*}\right) d N\left(\lambda_{t, d}^{*}\right) \\
d \xi=k_{\xi}\left(\xi^{*}-\xi\right) d t+\sigma_{\xi} d Z_{\xi}^{*} \\
d Z_{\chi}^{*} d Z_{\xi}^{*}=\rho d t\end{array}$ & $\begin{array}{l}F\left(t, T, S_{t}\right)=f(T)+\bar{\xi}^{*}\left(1-e^{-k_{\xi} \tau}\right)-\frac{\phi_{\chi}}{k_{\chi}}\left(1-e^{-k_{\chi} \tau}\right) \\
+e^{-k_{\chi} \tau} \chi_{t}+e^{-k_{\xi} \tau} \xi_{t}+\sum_{i=u p, d o w n} \lambda_{i, T}\left(1-e^{-k \tau}\right) \eta_{i}^{*}\end{array}$ \\
\hline
\end{tabular}


Table 4: Summary of theoretical models and formulas. Log-Price specification.

\begin{tabular}{|c|c|c|}
\hline Model & Risk-neutral specification & Futures Price Formula \\
\hline $\begin{array}{l}\text { Short -term: } \\
\text { MR } \\
\text { Long-term: } \\
\text { ABM } \\
\text { Jump: } \\
\text { Gaussian }\end{array}$ & $\begin{array}{l}\ln S_{t}=f(t)+\chi_{t}+\xi_{t} \\
d \chi_{t}=\left(-k \chi_{t}+\phi_{\chi}\right) d t+\sigma_{\chi} d Z_{\chi}^{*}+J\left(\mu_{J}^{*}, \sigma_{J}^{2}\right) d \Pi\left(\lambda_{t}^{*}\right) \\
d \xi=k_{\xi}\left(\xi^{*}-\xi\right) d t+\sigma_{\xi} d Z_{\xi}^{*} \\
d Z_{\chi}^{*} d Z_{\xi}^{*}=\rho d t\end{array}$ & $\begin{array}{l}F_{1 a}\left(\tau, S_{t}\right)=\exp \left(f(T)-\frac{\phi_{\chi}}{k}\left[1-e^{-k \tau}\right]+\mu_{\xi}^{*} \tau+\frac{\sigma_{\xi}^{2} \tau}{2}+\frac{\sigma_{\chi}^{2}}{4 k}\left[1-e^{-2 k \tau}\right]+\frac{\sigma_{\chi} \sigma_{\xi} \rho}{k}\left[1-e^{-k \tau}\right]\right. \\
\left.+\xi_{t}+e^{-k \tau} \chi_{t}+B(\tau)\right) ; B(\tau)=\lambda_{T} \int_{t}^{T}\left(\exp \left(\mu_{J}^{*} e^{-k \tau}+\frac{1}{2} \sigma_{J}^{2} e^{-2 k \tau}\right)-1\right) d s\end{array}$ \\
\hline $\begin{array}{l}\text { Short-term } \\
\text { factor: MR } \\
\text { Long-term } \\
\text { factor: MR } \\
\text { Jump: } \\
\text { Gaussian }\end{array}$ & $\begin{array}{l}\ln S_{t}=f(t)+\chi_{t}+\xi_{t} \\
d \chi_{t}=-\left(k_{\chi} \chi_{t}+\phi_{\chi}\right) d t+\sigma_{\chi} d Z_{\chi}^{*}+J\left(\mu_{J}^{*}, \sigma_{J}^{2}\right) d \Pi\left(\lambda_{t}^{*}\right) \\
d \xi_{t}=\left(\mu_{\xi}-\phi_{\xi}\right) d t+\sigma_{\xi} d Z_{\xi}^{*} \\
d Z_{\chi}^{*} d Z_{\xi}^{*}=\rho d t\end{array}$ & $\begin{array}{l}F_{2 a}\left(t, T, S_{t}\right)=\exp \left(f(T)-\frac{\phi_{\chi}}{k_{\chi}}\left[1-e^{-k_{\chi} \tau}\right]+\xi^{*}\left[1-e^{-k_{\xi} \tau}\right]+\frac{\sigma_{\chi}^{2}}{4 k_{\chi}}\left[1-e^{-2 k_{\chi} \tau}\right]\right. \\
\left.+\frac{\sigma_{\xi}^{2}}{4 k_{\xi}}\left[1-e^{-2 k_{\xi} \tau}\right]+\frac{\sigma_{\chi} \sigma_{\xi} \rho}{k_{\chi}+k_{\xi}}\left[1-e^{-\left(k_{\chi}+k_{\xi}\right) \tau}\right]+e^{-k_{\chi} \tau} \chi+e^{-k_{\xi} \tau} \xi_{t}+B(\tau)\right)\end{array}$ \\
\hline $\begin{array}{l}\text { Short-term } \\
\text { factor: MR } \\
\text { Long-term } \\
\text { factor: } \\
\text { ABM } \\
\text { Jump: } \\
\text { Exponential }\end{array}$ & $\begin{array}{l}\ln S_{t}=f(t)+\chi_{t}+\xi_{t} \\
d \chi_{t}=-\left(k_{\chi} \chi_{t}+\phi_{\chi}\right) d t+\sigma_{\chi} d Z_{\chi}^{*}+J_{u}^{*}\left(\eta_{u}^{*}\right) d N\left(\lambda_{u}^{*}\right)-J_{d}^{*}\left(\eta_{i}^{*}\right) d N\left(\lambda_{d}^{*}\right) \\
d \xi_{t}=\left(\mu_{\xi}-\phi_{\xi}\right) d t+\sigma_{\xi} d Z_{\xi}^{*} \\
d Z_{\chi}^{*} d Z_{\xi}^{*}=\rho d t\end{array}$ & $\begin{array}{l}F_{1 b}\left(t, T, S_{t}\right)=\exp \left(f(T)-\frac{\phi_{\chi}}{k}\left[1-e^{-k \tau}\right]+\left(\mu_{\xi}-\phi_{\xi}\right) \tau+\frac{\sigma_{\xi}^{2} \tau}{2}+\frac{\sigma_{\chi}^{2}}{4 k_{\chi}}\left[1-e^{-2 k} \tau\right]\right. \\
\left.+\frac{\sigma_{\chi} \sigma_{\xi} \rho}{k_{\chi}}\left[1-e^{-k \chi \tau}\right]+\xi_{t}+e^{-k_{\chi} \tau} \chi_{t}+C(\tau)\right) ; C(\tau)=\sum_{i=u p, d o w n} \frac{\lambda_{T, i}}{k}\left(\frac{\eta_{J, i}^{*} \exp (-k \tau)-1}{\eta_{J, i}^{*}-1}\right)\end{array}$ \\
\hline $\begin{array}{l}\text { Short-term } \\
\text { factor: MR } \\
\text { Long-term } \\
\text { factor: MR } \\
\text { Jump: } \\
\text { Exponential }\end{array}$ & $\begin{array}{l}\ln S_{t}=f(t)+\chi_{t}+\xi_{t} \\
d \chi_{t}=\left(-k \chi_{t}+\phi_{\chi}\right) d t+\sigma_{\chi} d Z_{\chi}^{*}+J_{u}^{*}\left(\eta_{u}^{*}\right) d N\left(\lambda_{u}^{*}\right)-J_{d}^{*}\left(\eta_{d}^{*}\right) d N\left(\lambda_{d}^{*}\right) \\
d \xi=k_{\xi}\left(\xi^{*}-\xi\right) d t+\sigma_{\xi} d Z_{\xi}^{*} \\
d Z_{\chi}^{*} d Z_{\xi}^{*}=\rho d t\end{array}$ & $\begin{array}{l}F_{2 b}\left(t, T, S_{t}\right)=\exp \left(f(T)-\frac{\phi_{\chi}}{k_{\chi}}\left[1-e^{-k_{\chi} \tau}\right]+\bar{\xi}^{*}\left[1-e^{-k_{\xi} \tau}\right]+\frac{\sigma_{\chi}^{2}}{4 k_{\chi}}\left[1-e^{-2 k_{\chi} \tau}\right]\right. \\
\left.+\frac{\sigma_{\xi}^{2}}{4 k_{\xi}}\left[1-e^{-2 k_{\xi} \tau}\right]+\frac{\sigma_{\chi} \sigma_{\xi} \rho}{k_{\chi}+k_{\xi}}\left[1-e^{-\left(k_{\chi}+k_{\xi}\right) \tau}\right]+e^{-k_{\chi} \tau} \chi+e^{-k_{\xi} \tau} \xi_{t}+C(\tau)\right)\end{array}$ \\
\hline
\end{tabular}


We will focus in Model 1a (price level specification) with more detail for exposition reasons.

\section{Model 1a (Price Level):}

Mean Reverting (MR) short term factor with Gaussian jump size + Arithmetic Brownian Motion (ABM) equilibrium level.

For exposition reason we present again Model 1a (price level) under the empirical probability measure. That is in this model electricity price is assumed to be described by the following specification:

$$
\begin{aligned}
& S_{t}=f(t)+\chi_{t}+\xi_{t} \\
& d \chi=-k \chi d t+\sigma_{\chi} d Z_{\chi}+J\left(\mu_{J}, \sigma_{J}\right) d \Pi\left(\lambda_{t}\right) \\
& d \xi=\mu_{\xi} d t+\sigma_{\xi} d Z_{\xi} \\
& d Z_{\chi} d Z_{\xi}=\rho d t
\end{aligned}
$$

In words, electricity price is given by the sum of three components. The first one is a deterministic seasonal function (e.g. sinusoidal specification), the second and third components are non-observable state variables. $\chi$ captures the short-term movements of electricity price, it is a mean-reverting process with jumps. Probability of occurrence of jumps is given by $\lambda_{t}$, and given a jump occurrence the jump size follows a Gaussian distribution, with mean $\mu_{J}$ and standard deviation $\sigma_{J}$. Finally, $\xi$ represents the long-term equilibrium level, and is given by an ABM, in this specification.

In order to value derivatives one has to use risk-neutral processes to describe the evolution of the underlying state variables. In our model we have to introduce two additional parameters $\phi_{x}$ and $\phi_{\xi}$ that specify constant reductions in the drifts for each process. Moreover, the mean jump size $\left(\mu_{\mathrm{J}}\right)$ and the mean probability of observing a jump ( $\lambda$ ) may also be different under the risk-neutral measure. As we stated before we assume the intensity process under the objective and risk-neutral measure are the same, therefore all jump risk premium will be "artificially" captured by jump-size risk premium.

Specifically, we assume that under the equivalent (or risk-neutral) martingale measure the stochastic processes are of the form: 


$$
\begin{aligned}
& S_{t}=f(t)+\chi_{t}+\xi_{t} \\
& d \chi=-\left(k \chi+\phi_{\chi}\right) d t+\sigma_{\chi} d Z_{\chi}^{*}+J\left(\mu_{J}^{*}, \sigma_{J}\right) d \Pi\left(\lambda_{t}\right) \\
& d \xi=\left(\mu_{\xi}-\phi_{\xi}\right) d t+\sigma_{\xi} d Z_{\xi}^{*} \\
& d Z_{\chi}^{*} d Z_{\xi}^{*}=\rho d t
\end{aligned}
$$

where $\phi_{\chi}$ and $\phi_{\xi}$ are the market prices of risk for short-term and long-term uncertainty, respectively. We assume both are constant ${ }^{11} \cdot \mu_{J}^{*}$ is the mean jump-size under the riskneutral measure. As we stated before, it will capture jump risk premia, since we have made the simplifying assumption there is no jump risk intensity premia.

By using the ODE approach (equations $7 \mathrm{a}-7 \mathrm{~b}$ with $u=(0,0)$ and $v=(1,1)$ ), the price of the future contract under this model is given by the following equation (detailed derivation in the Appendix):

$$
F\left(t, T, S_{t}\right)=f(T)+\mu_{\xi}^{*} \tau-\frac{\phi_{\chi}}{k}\left(1-e^{-k \tau}\right)+e^{-k \tau} \chi_{t}+\xi_{t}+\lambda(t, T) \frac{\mu_{J}^{*}}{k}\left(1-e^{-k \tau}\right)
$$

where $\tau=T-t, \mu_{\xi}^{*}=\mu_{\xi}-\phi_{\xi}$ is the risk-adjusted equilibrium drift, and $\lambda(t, T)$ represents the stepwise intensity function, and is composed by four quarterly dummies (fall, winter, spring and summer).

We may see the futures price is mainly composed by four components. The first term $f(T)$ is related to the seasonal (deterministic) beha viour of electricity prices, the second component captures the diffusive risk premiums (long-term and short-term uncertainty), and is given by $\mu_{\zeta}^{*} \tau-\frac{\phi_{\chi}}{k}\left(1-e^{-k \tau}\right)$, the third component captures the actual short-term deviation and equilibrium level $\left(e^{-k \tau} \chi_{t}+\xi_{t}\right)$, and the last term captures the jump component.

Bessembinder and Lemmon (2002) predict in electricity markets should exist a seasonal risk premium $^{12}$ related to the skewness of the underlying variable. In particular, with low demand risk (so low skewness) the risk premium should be negative while during periods of high demand risk (high skewness in the spot price) risk

\footnotetext{
${ }^{11}$ Although alternative specifications could be included.

${ }^{12}$ Risk Premium $\left(R P_{t}\right)$ is defined as the difference between the current futures price and the expected price on delivery date, i.e. $R P_{t}=F(t, T, S)-E_{t}^{P}\left(S_{T}\right)$, where expectation operator is calculated under the objective probability measure.
} 
premium is positive. Note that effectively our pricing formula is able to capture this pattern, given the relationship between jumps and skewness of the underlying distribution. During periods where the probability of jumps is zero (or in situations with $\mu_{J}^{*} \approx \mu_{J}$ ), the risk premium will be mainly driven by $\phi_{x}$. Given the empirical evidence reported by $\mathrm{BL}$ and $\mathrm{PJ}$ for the PJM market, our model is able to replicate that pattern if $\phi_{\chi}>0$ and $\mu_{J}^{*}>\mu_{J}$. This would imply producers are willing to sell forward during "low skewness periods", ie. when the probability of jumps is low, while there is an important jump risk premium in the other periods, so distributors are willing to buy forward although they have to pay a big risk premium.

In particular we are able to derive an explicit formula for the risk premium. In particular, the expected value of $S_{T}$ at $t$ under the objective probability measure $(P)$ is given by the following expression:

$$
E_{t}^{P}\left(S_{T}\right)=f(T)+\mu_{\xi} \tau+e^{-k \tau} \chi_{t}+\xi_{t}+\lambda(t, T) \frac{\mu_{J}}{k}\left(1-e^{-k \tau}\right)
$$

and therefore we can obtain an explicit formula for risk premium under Model 1a, and we can check the close connection between risk premium and skewness. In particular, if skewness is seasonal (through seasonality in jumps) we will have seasonality in risk premium $\left(R P_{t}\right)$. That is,

$$
R P_{t} \equiv F(t, T, S)-E_{t}^{P}\left(S_{T}\right)=-\left(\phi_{\xi} \tau+\frac{\phi_{\chi}}{k}\left(1-e^{-k \tau}\right)\right)+\lambda(T)\left(\frac{\mu_{J}^{*}-\mu_{J}}{k}\right)\left(1-e^{-k \tau}\right)
$$

It must be noted the first part of the formula $\left(\phi_{\xi} \tau+\frac{\phi_{\chi}}{k}\left(1-e^{-k \tau}\right)\right)$ corresponds to the risk premium for diffusive risk. This is the kind of risk premium that may be generated with the models proposed by Schwartz and Smith (2000) and Lucia and Schwartz (2002). It must be noted these models cannot generate seasonality in risk premium. Therefore, these models cannot generate the pattern of risk premium predicted by Bessembinder and Lemmon (2002) if skewness is non-constant. The last term of the equation, $\lambda(T)\left(\frac{\mu_{J}^{*}-\mu_{J}}{k}\right)\left(1-e^{-k \tau}\right)$ is the one that corresponds to the jump effect, and is one of the 
main contributions of this paper. Therefore with our extension we are able to generate seasonality in risk premium as predicted by Bessembinder and Lemmon (2002). Again, the seasonality in risk premium following Bessembinder and lemmon (2002) is generated through "skewness risk premium".

In the next section we report an empirical analysis and we show the kind futures curve pattern our models may generate. We have to say the empirical section is still preliminary and at this stage the section tries to illustrate the kind of behavior futures curve may exhibit under our models. We have estimated some parameters from spot price series following the methodology proposed by Escribano, et al. (2002), and we have calibrated risk-neutral parameters from forward data.

\section{EMPIRICAL APPLICATION: PJM SPOT AND FORWARD DATA.}

In this section we provide an empirical application with data from the PJM market. The goal of this section is to show how futures contracts curves behave under our specifications (in particular under Model 1a, price level). Moreover, we show how to estimate risk-neutral parameters from traded contracts that could be useful for the valuation of other types of derivatives. We also analyse the relative importance of risk premium over forward price.

The PJM (Pennsylvania-New Jersey-Maryland) market is among the most liquid and developed electricity markets. Moreover the rapid growing literature on electricity forward pricing has focused on a major extent on this market (Bessembinder and Lemmon, 2002; Longstaff and Wang, 2002; Pirrong and Jermakyan, 2000 among others). A detailed analysis of the behavior of electricity prices (under the empirical probability measure) for this and other markets has been done in Escribano et al. (2002).

In Appendix A.2. we report some summary statistics for electricity price and log-price series. We also plot price series and the shape of the unconditional empirical distribution of price series. One of the first conclusions may be obtained, and outlined previously by Escribano et al. (2002) is the importance of spikes in the PJM market. We may see a high degree of skewness, that is generated by the occurrence of extreme observations (jumps) that are quite important in this market. We may also observe from the plot of spot price series, extreme observations have a seasonal pattern, and are concentrated in summer that is in those months with higher demand. We will corroborate this point with the formal estimation of the seasonal (through quarterly 
dummies) specification for $\lambda_{t}$, again see also results obtained by Escribano, Peña and Villaplana (2002).

We have spot and forward data for the period January 1997 - March 2000. Data has been obtained through Bloomberg. This sample period is similar to the period analysed by Bessembinder and Lemmon (2002) and Pirrong and Jermakyan (2000) and allow us to compare the results with those obtained by these authors.

\section{1.- Estimation procedure}

The estimation procedure is performed in two steps.

a) estimate the process under the empirical probability measure with spot data from January 1997 - December 1998 (we also have estimated the process with the sub-sample January 1998 - December 1998).

b) estimate the remaining parameters (under the risk-neutral probability measure) with forward data for the period January 1999 - March 2000.

We present results for Model 1a (price level). We have estimated the model following the methodology proposed in Escribano et al. (2002), see also Knittel and Roberts (2001), and Geman and Roncoroni (2003) ${ }^{13}$. In this way we are able to obtain estimates for $\left\{f(t), k, \sigma_{\chi}, \lambda_{t}, \mu_{J}, \sigma_{J}, \mu_{\xi}\right\}$. The remaining estimates needed to build the forward curve are those related to the market prices of risk $\left\{\phi_{\chi}, \phi_{\xi}, \mu_{J}^{*}\right\}$.

With the first set of parameters (those that do not change under the objective and under the risk-neutral probability measure,) we may calculate the expected (under the objective probability measure) price on delivery (i.e. by fixing $\phi_{x}=\phi_{\xi}=0$ and $\mu_{J}^{*}=\mu_{J}$ in the price formula). Therefore we can analyse the behaviour of the risk premium in a clearer way. In other words, with the estimated parameters we calculate the price of the future contract under the objective probability measure (i.e. assuming no risk premium). So we may show how risk premium affect the behaviour of the forward curve, and we show that effectively our model captures the main characteristics presented in BL and PJ . Moreover, our model is much easier to estimate and is useful

\footnotetext{
${ }^{13}$ Other approaches may be used in this first step. For instance, we could estimate the parameters applying the Kalman filter to the spot price series. We could "robustify" the use of the Kalman filter by detecting previously the "outliers" or by imposing some level (three standard deviations) and eliminate those observations above it.

We want to emphasize there could be different econometric methodologies to estimate parameters in this first step. The results should not differ qualitatively on the exact econometric procedure the analyst uses in this first step.
} 
for extracting risk premium and for the pricing of European options (by inversion of the characteristic function).

We provide a summary table with the estimated parameters. We have not provided in the table the parameters corresponding to the seasonal function $f(t)$, but more detailed results about the estimated parameters are reported in Appendix A.4.

Table 5. Summary estimated parameters ${ }^{14}$, PJM. (Jan. 1998 - Dec. 1998). (t-stat. in parenthesis)

\begin{tabular}{|l|l|l|l|l|}
\hline$k$ & $\sigma_{\chi}$ & $\lambda_{\text {summer }}$ & $\mu_{J}$ & $\sigma_{J}$ \\
\hline 0.73 & 7.61 & 0.17 & 68.57 & 78.27 \\
$(8.85)$ & $(32.81)$ & $(3.19)$ & $(1.86)$ & $(3.07)$ \\
\hline
\end{tabular}

From the estimation results we have obtained $\mu_{\xi}$ is not statistically significant. From the graphical representation of electricity prices we may see there was not a clear trend (upward or downward) so equilibrium price remains constant during the analysed period. We also may observe probability of observing jumps is only statistically significant for summer months. Finally we have obtained, a high degree of mean reversion, since $k$ is 0.7 , this imply a half-life of shocks of one-day approximately. This would be consistent with the results provided by Pirrong and Jermakyan (2000). They analysed load mean-reversion with hourly data and found half-life of load shocks to be 10 hours.

With the estimated parameters form electricity spot prices we perform the second step. We estimate the remaining parameters from daily one-month forward contracts for the period January 1999 - March 2000 . Since $\mu \xi$ was not found to be statistically significant and since we just have one- month maturity contracts we have imposed $\phi_{\xi}=0$.

We performed estimation for two different specifications for the risk-neutral mean jump size parameter, $\mu_{J}^{*}$. In the first one (specification A) the parameter is constant while in specification B we allow it to be seasonal. We allow risk-neutral mean jump size to be different for contracts with delivery in June, July and August, trough the following specifications,

$$
\mu_{J}^{*}=\mu_{J, \text { May }}^{*} \cdot D^{\text {May }}+\mu_{J, \text { June }}^{*} \cdot D^{\text {June }}+\mu_{J, \text { July }}^{*} \cdot D^{\text {July }}
$$

\footnotetext{
${ }^{14}$ Although the intensity process is specified by quarterly dummies, we could use a more detailed specification, with monthly summer dummies. More detailed results upon request.
} 
where $D^{i}$ is a monthly dummy variable that takes value 1 if the observation is on the $i$ month and zero otherwise.

Estimation is carried out by minimising the squared error between observed forward prices and model's prices.

Summary results are reported in the following table:

Table 6. Risk-neutral estimates.

\begin{tabular}{|l|l|l|l|l|l|l|}
\hline $\begin{array}{l}\text { Parameter } \\
\text { (std.error) }\end{array}$ & $\phi_{\chi}$ & $\mu_{J}^{*}$ & $\mu_{J, \text { May }}^{*}$ & $\mu_{J, \text { June }}^{*}$ & $\mu_{J, J u l y}^{*}$ & $\begin{array}{l}\text { Sum Squared } \\
\text { Residuals }\end{array}$ \\
\hline Specification A & -2.34 & 174.18 & - & - & - & 18917.87 \\
& $(0.39)$ & $(5.17)$ & & & & \\
\hline Specification B & -2.14 & - & 67.89 & 198.25 & 204.47 & 5709.00 \\
& $(0.20)$ & & $(4.29)$ & $(4.10)$ & $(4.19)$ & \\
\hline
\end{tabular}

From this results we observe risk premium is clearly seasonal in PJM forward market. During all months but summer, forward price bias is positive and small, while for forward contracts with delivery in summer bias is much higher. This bias, or risk premium is concentrated on forward contracts for delivery in July and August. We also see the size of "forward premium" is very important during summer months, that is "jump risk premium" is one of the main determinants of forward prices for summer delivery months. In particular, we can explicitly calculate the relative importance of "jump risk premium" through equation (10) and the results provided in Table 5 and 6. From the estimated parameters. We may see "jump risk premium" represents $40 \%$ of the forward price in June and July (that is for those contracts with maturity in July and August).

We see from Figure A.4.1, our model is able to replicate the observed pattern in PJM forward contracts. During those months where there is a positive probability of observing a jump, jump risk premium is relatively more important, so distributors (i.e. those agents that are exposed to price spikes) are willing to buy forward, so there is demand pressure on forwards and the price of these contracts increases so futures market clears. 
An interesting point is that model's futures prices are smoother than those observed in the market. We report model's futures prices but imposing a lower degree of meanreversion (in particular we fixed $k=0.15$ ). As may be seen from Figure A.4.2, the pattern of forward prices generated by the model and those observed in the market are more similar. There are two possible explanations for this result. On one hand, it may be argued that traders overestimate the persistence of shocks in the spot market. This argument has been advanced by Pirrong and Jermakyan (2000). Since we are analysing a immature market, one could think this behavior would disappear and agent will learn shocks in spot market die out very fast, so futures prices will not react so much to shortterm deviations in spot market. Another alternative argument is time-varying diffusive risk premium. We have imposed market price of diffusive risk is constant $\left(\phi_{\chi}\right)$, but the model may be extended to allow short-term risk premium to be a linear function of the short-term deviations, this would introduce an additional degree of freedom in the pricing formula, that could capture the fact that futures prices "overreact" to shocks in the spot market.

Which of the two possible explanations is behind the observed pattern of forward contracts in the PJM market is an open question that requires further research.

\section{CONCLUSIONS AND FURTHER RESEARCH}

We have a presented a new comprehensive set of models for the valuation of electricity futures contracts. The models (specified as log-price and price models) are extensions of Schwartz and Smith (2000) long-term short-term model. The paper extends the fast growing literature on electricity pricing both in a theoretical and empirical way. Major extensions are:

a) the inclusion of jump component.

b) the introduction of an alternative specification for the long-term state variable

c) the application of the model to the PJM market,

d) explicitly incorporate (and provide a method for estimation) "jump risk premia" as one of the major determinants of the previously observed "seasonal risk premium" in the PJM market,

At the same time we extend the insights from Bessembinder and Lemmon (2002) equilibrium model and relate them to observable seasonal jump behavior (that generate non-constant skewness) and jump risk premium. 
Summarizing, we have provided a new set of models, and a new pricing formula for the valuation of electricity forward contracts. One of our main contributions is the introduction of a jump component. Given the characteristics of electricity prices, jumps do play a central role in the evolution of electricity spot prices and electricity forward prices. In particular we also have shown jump size risk premium represents $40 \%$ of summer delivery forward prices.Empirically we have also provided a methodology for obtaining risk-neutral parameters estimates.

Since the model is specified in a jump-diffusion framework we can use the results from Duffie, Pan and Singleton (2000) for the pricing of European options (by inversion of the characteristic function).

Although more work needs to be done, we consider this version of the paper is able to show the strengths of our approach.

There also exist some possible extensions:

On one hand, we plan to extend the empirical application of the model to other markets. Escribano, Peña and Villaplana (2002) shown jumps also play a role in explaining the behavior of electricity prices from Nordpool. Lucia and Schwartz (2002) applied the model of Schwartz and Smith (2000) to NordPool derivatives. Since Escribano, Peña and Villaplana (2002) found jumps are also important in NordPool, it seems natural to apply our new valuation formulas to NordPool, were probably we will be able to obtain better pricing results than the pure diffusion model of Lucia and Schwartz (2000). This is the focus of an ongoing research project.

On the other hand, another interesting extension would be to include the possibility of time-varying (affine) diffusive risk premium. This alternative may be interesting in order to analyse if the volatility of forward prices is due to the overestimation of perisistence by traders in a new and immature market or is due to time-varying diffusive risk premium. 


\section{APPENDIX}

\section{A.1.- RELATIONSHIP BETWEEN FUTURES PRICES AND TRANSFORMS}

In this section we will show the relationship between the transforms $\Psi(u, X, t, T)$ and $\Phi(v, u, X, t, T)$ and the price of the futures contract. We will show that knowledge of $\Psi$ and $\Phi$ completely determines the price of the future contract. Therefore in this set up finding the pricing formula will be equivalent to solve the corresponding system of ODE (4a-4b) and (7a-7b) and depending on the assumption made about the evolution of the underlying state variables.

Assuming constant interest rates, the futures (or forward) price of a contract with maturity $\mathrm{T}$ is equal to the expected price of the commodity at $\mathrm{T}$ where the expectation is taken under the equivalent martingale (or risk-neutral) measure. Therefore, the price of a futures contract at $\mathrm{t}$, with maturity $\mathrm{T}$ is given by the following expression:

$$
F\left(t, T, S_{T}\right)=E_{t}^{Q}\left(S_{T}\right)
$$

We can make use of DPS results if the variable of interest is linear in the state variables.

We have two different sets of models depending if we model the spot price $\left(S_{t}\right)$ or the $\log$-spot price $\left(\log S_{t}\right)$. In any of both cases state variables enter in a linear way, so we have:

\section{1.-Log-spot price models: $\ln S_{t}=f(t)+\chi_{t}+\xi_{t}$}

In this case we can re-express the futures price as a function of $\Psi$ :

$$
\begin{aligned}
& F(t, T, S)=E_{t}^{Q}\left(S_{T}\right)=e^{r \tau} E_{t}^{Q}\left(e^{-r \tau} e^{\ln S_{T}}\right)=e^{r \tau} E_{t}^{Q}\left(e^{-r \tau} e^{f(T)+\chi_{T}+\xi_{T}}\right)= \\
& =e^{r \tau+f(T)} E_{t}^{Q}\left(e^{-r \tau} e^{u \cdot X_{T}}\right)=e^{r \tau+f(T)} \Psi(u, X, t, T)
\end{aligned}
$$

where $u=(1,1)$ and $X=(\chi, \xi)$. Therefore for each of the four models we have proposed (Model 1a, 1b, 2a, 2b) we have to derive the corresponding transform since once we know it we can derive in a straightforward way the price of the future contract, see Table 3 for the future pricing formula for each of the four models.

2.- Spot price models $S_{t}=f(t)+\chi_{t}+\xi_{t}$

In this case we can re-express the futures price as a function of $\Phi$ :

$$
\begin{aligned}
& F(t, T, S)=E_{t}^{Q}\left(S_{T}\right)=f(T)+e^{r \tau} E_{t}^{Q}\left(e^{-r \tau}\left(\chi_{T}+\xi_{T}\right)\right)= \\
& =f(T)+e^{r \tau} \Phi(v, u, X, t, T)
\end{aligned}
$$

where in this case $v=(1,1), u=(0,0)$, and $X=(\chi, \xi)$. And again as in the case of logspot price models, in order to derive the pricing formulas for the four models (see Table 4) we have to find the corresponding "extended" transform. 


\section{A.2.- SUMMARY STATISTICS AND GRAPHS}

We provide summary statistics for daily spot price and log-price series of PJM market (Pennsylvania - New Jersey - Maryland (PJM)). Period: January 1997 - March 2000

Table A.2.1: Summary Statistics for Price and Log-Price PJM spot prices.

\begin{tabular}{|l|l|l|l|l|l|l|l|l|}
\hline Series & N. Obs. & Mean & Med. & Min. & Max. & Std.Dev. & Skew. & Kurt. \\
\hline Price & 822 & 30.39 & 23.42 & 10.56 & 573.18 & 39.89 & 8.42 & 81.46 \\
\hline Log-Price & 822 & 3.23 & 3.15 & 2.36 & 6.35 & 0.45 & 2.98 & 14.12 \\
\hline
\end{tabular}


Figure A.2.1: Price series PJM market.

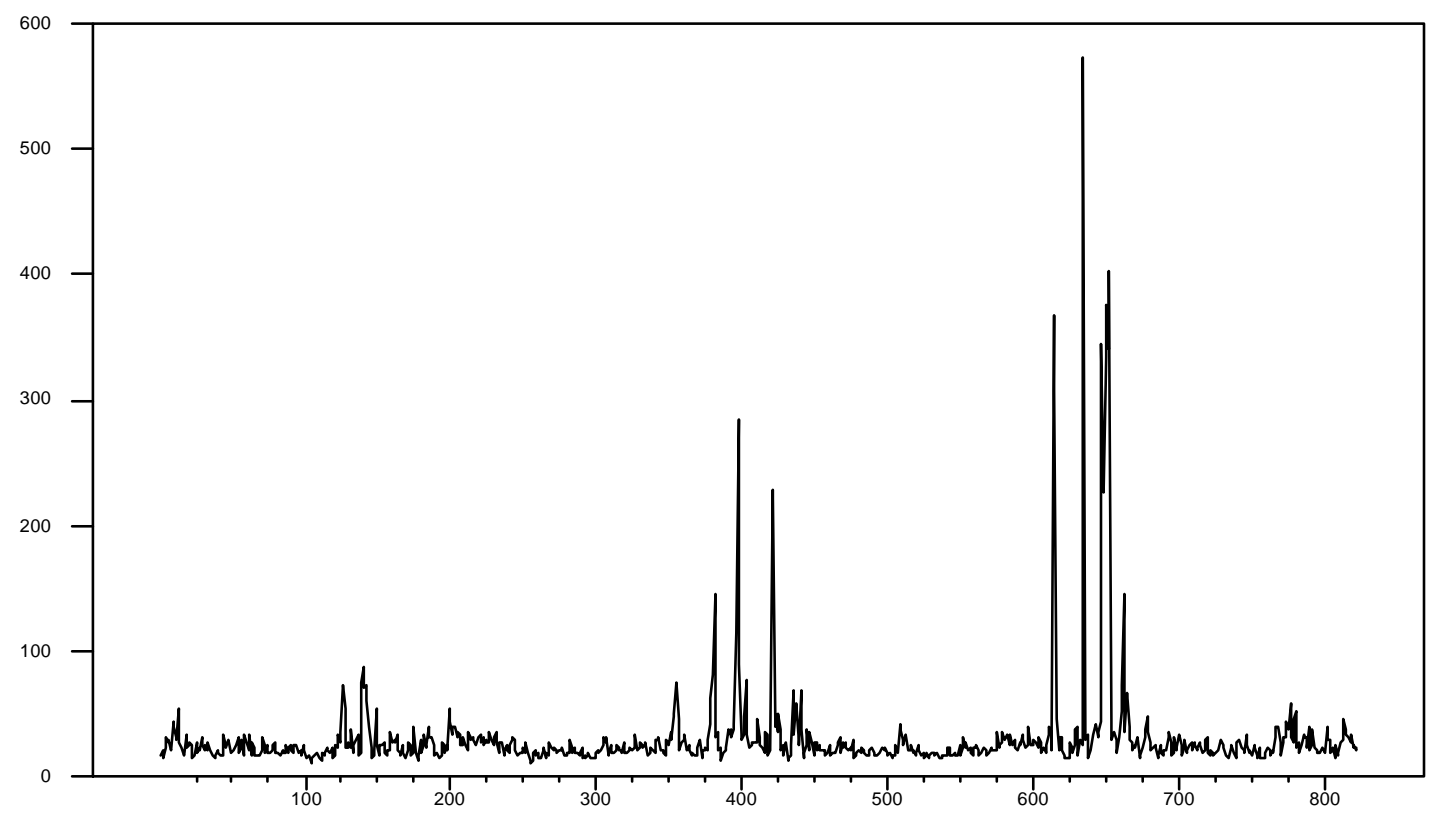

Figure A.2.2: Empirical distribution, PJM Price Series.

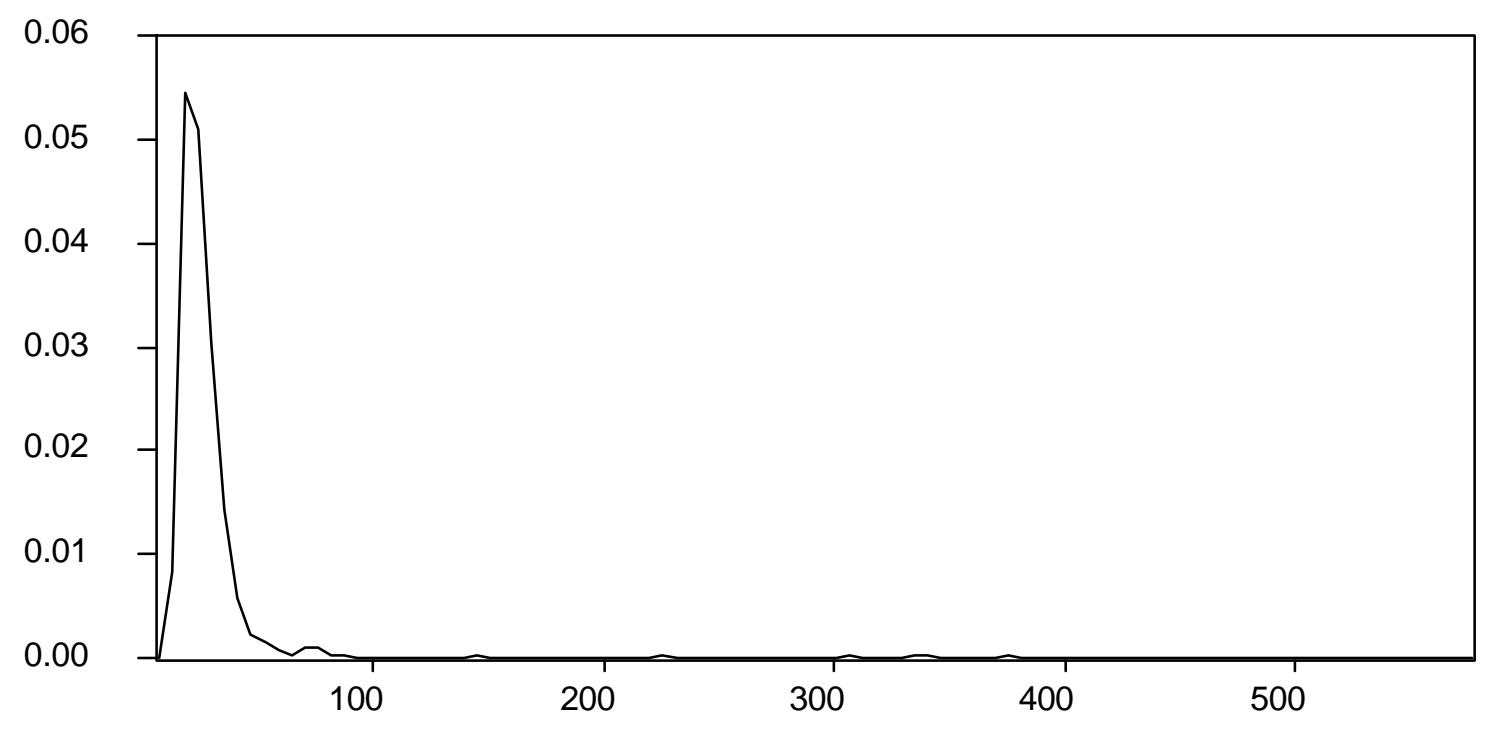


Figure A.2.3: Daily Observations One-Month Forward Price. PJM.

Janua ry 1997 - March 2000 (822 observations)

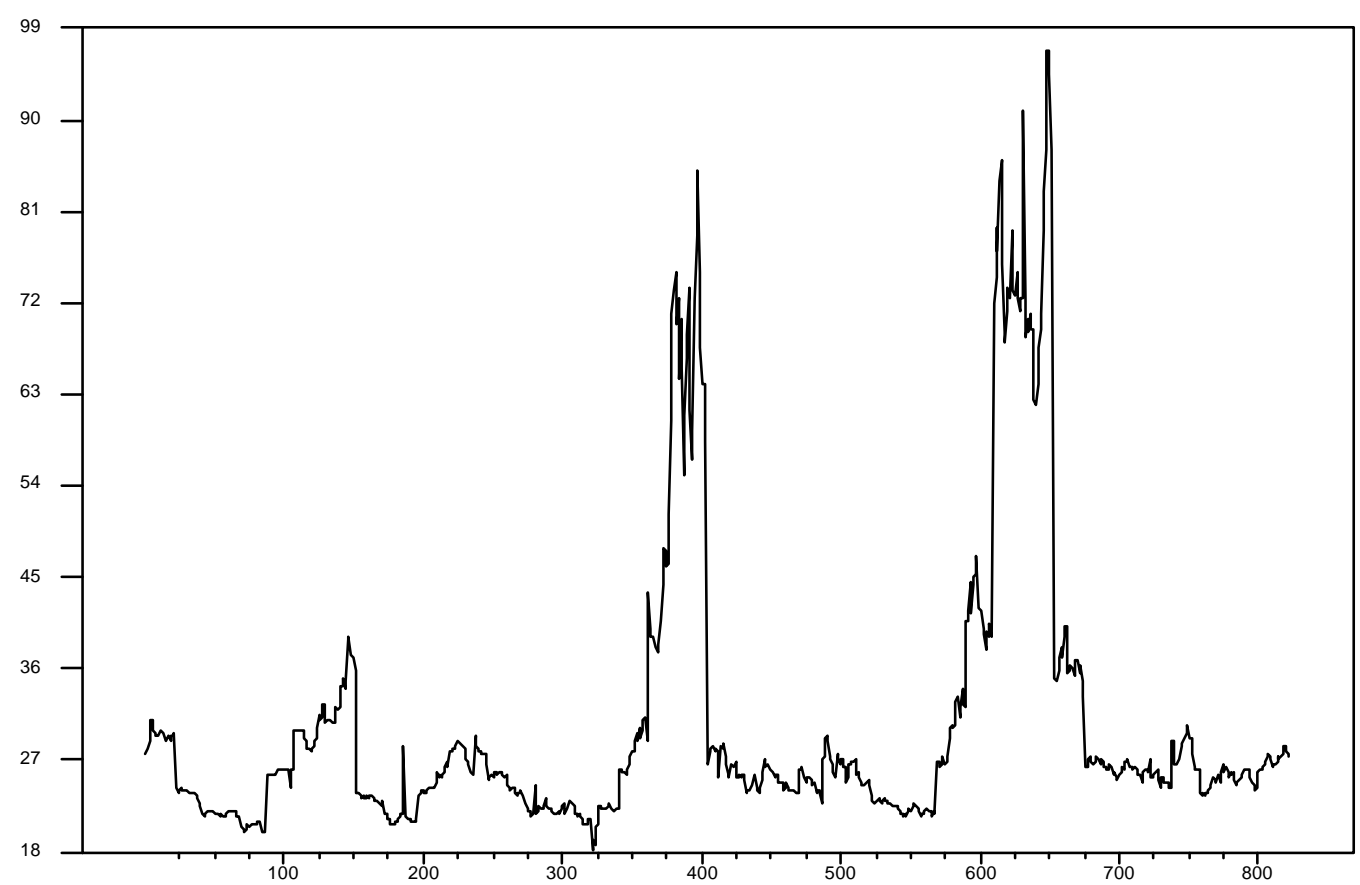




\section{A.3- DETAILED DERIVATION FUTURES PRICING FORMULA: TWO- FACTOR MODELS WITH GAUSSIAN JUMPS. PRICE LEVEL MODEL.}

For expositional reasons we provide the detailed derivation for Model 1a, price level. We outline the "ODE approach" presented in equations (7a-7b). Details for the other models may be obtained from request.

$$
\begin{aligned}
& P_{t}=f(t)+\chi_{t}+\xi_{t} \\
& d \chi=k\left(\alpha^{*}-\chi\right) d t+\sigma_{\chi} d Z_{\chi}^{*}+J\left(\mu_{J}^{*}, \sigma_{J}\right) d \Pi\left(\lambda_{t}\right) \\
& d \xi=\mu_{\xi}^{*} d t+\sigma_{\xi} d Z_{\xi}^{*} \\
& d Z_{\chi}^{*} d Z_{\xi}^{*}=\rho d t
\end{aligned}
$$

where $\alpha^{*} \equiv \frac{-\lambda_{\chi}}{k}$ and $\mu_{\zeta}^{*} \equiv \mu_{\zeta}-\lambda_{\zeta}$. Since we are dealing with a price model in order to calculate the futures price we have to calculate the "extended" transform with $v=(1,1)$ and

$u=(0,0)$. It can be shown, $u=(0,0) \Rightarrow \beta\left(u_{1}, u_{2}\right)=(0,0)$.

Therefore we have the following system of ODE:

$$
\begin{aligned}
& -\dot{B}_{1}=-k B_{1} ; B_{1}(T)=v_{1} \Rightarrow B_{1}\left(v_{1}, t, T\right)=v_{1} e^{-k(T-t)} \\
& -\dot{B}_{2}=0 ; B_{2}(T)=v_{2} \Rightarrow B_{2}\left(v_{2}, t, T\right)=v_{2} \\
& -\dot{A}=k \alpha^{*} B_{1}+\mu_{\xi}^{*} B_{2}+\beta^{T} H_{0} B+l_{0} \nabla \theta(\beta) B_{1} \\
& \Rightarrow A(t)=\mu_{\xi}^{*}(T-t)+\alpha^{*}\left(1-e^{-k(T-t)}\right)+\lambda(t, T) \frac{\mu_{J}^{*} v_{1}}{k}\left(1-e^{-k(T-t)}\right)
\end{aligned}
$$

and by equation (A.2) we have:

$$
\begin{aligned}
& F(P, t, T)=f(T)+\left.e^{r(T-t)} \Phi(v, u, \chi, \xi, t, T)\right|_{\substack{u=(0,0) \\
v=(1,1)}}= \\
& =f(T)+e^{r(T-t)} \Psi((0,0), t, T)\left(A(t)+B_{1}(t) \chi+B_{2}(t) \xi\right)= \\
& =f(T)+\mu_{\xi}^{*}(T-t)+\alpha^{*}\left(1-e^{-k(T-t)}\right)+e^{-k(T-t)} \chi_{t}+\xi_{t}+\lambda(t, T) \frac{\mu_{J}^{*}}{k}\left(1-e^{-k(T-t)}\right)
\end{aligned}
$$




\section{A.4.- ESTIMATION RESULTS: PJM}

In order to obtain the values for the empirical exercise we have estimated an AR(1) process with deterministic seasonality and jumps. We have followed the estimation methodology proposed by Escribano et al. (2002). We have introduced a deterministic time trend, the estimated parameter (B2) is the one corresponding to $\mu_{\xi}$. It must also be noted the relationship between the autoregressive parameter $(\phi)$ and $k$, i.e. $1-\phi=k$.

Autoregressive $(\mathrm{AR}(1))$, pure jump model, intensity of the Poisson process time dependent.

$$
\begin{gathered}
P_{t}=f(t)+X_{t} \\
X_{t}=\left\{\begin{array}{c}
\phi X_{t-1}+\sigma \cdot \varepsilon_{1 t} ; \text { prob. } 1-\lambda_{t} \\
\\
\phi X_{t-1}+\sigma \cdot \varepsilon_{1 t}+\mu_{J}+\sigma_{J} \cdot \varepsilon_{2 t} ; \text { prob. } \lambda_{t}
\end{array}\right. \\
\lambda_{t}=L 1 \cdot \text { fall }_{t}+L 2 \cdot \text { winter }_{t}+L 3 \cdot \text { spring }_{t}+L 4 \cdot \text { summer }_{t} \\
\varepsilon_{1 t}, \varepsilon_{2 t} \sim \text { i.i.d. } N(0,1)
\end{gathered}
$$

In particular, we have specified the seasonal function $f(t)$ by means of monthly dummies, so the specification we have used is the following: $f(t)=\sum_{i=1}^{12} M_{i} \cdot D_{i}^{M}$, where $D_{i}^{M}$ is a monthly dummy that takes value 1 if the observation lies in the ith-month and zero otherwise. $M_{i}$ are the corresponding coefficients.

On the other hand we have allowed the intensity process to have a seasonal structure. In particular we allow the probability of observing a jump to be different depending on the season. Winter is defined as months December, January and February. The other seasons are defined using consecutive three-month periods. 
Table A.4.1.- Estimated parameters PJM.

\begin{tabular}{|l|ll|ll|}
\hline & Sample & $01 / 97-12 / 98$ & Sample & $01 / 98-12 / 98$ \\
\hline Parameter & Coeff. & Std. Error & Coeff. & Std. Error \\
\hline$\phi$ & 0.28 & 0.03 & 0.23 & 0.03 \\
$M 1$ & 24.52 & 1.40 & 22.39 & 2.41 \\
$M 2$ & 20.55 & 2.69 & 19.46 & 4.59 \\
$M 3$ & 24.26 & 1.79 & 22.27 & 3.52 \\
$M 4$ & 22.42 & 2.70 & 23.38 & 3.81 \\
$M 5$ & 26.24 & 1.59 & 32.47 & 1.54 \\
$M 6$ & 23.04 & 2.01 & 22.71 & 2.41 \\
$M 7$ & 26.61 & 1.90 & 29.99 & 2.12 \\
$M 8$ & 25.65 & 2.32 & 28.95 & 2.75 \\
$M 9$ & 27.64 & 1.71 & 30.38 & 1.34 \\
$M 10$ & 27.33 & 1.75 & 22.75 & 3.52 \\
$M 11$ & 25.29 & 2.47 & 21.14 & 4.71 \\
$M 12$ & 20.80 & 2.74 & 19.23 & 5.76 \\
$\sigma$ & 7.11 & 0.16 & 7.61 & 0.23 \\
$L 4$ & 0.17 & 0.04 & 0.17 & 0.05 \\
$\mu_{J}$ & 48.97 & 28.34 & 68.57 & 36.94 \\
$\sigma_{J}$ & 61.26 & 12.37 & 78.27 & 25.53 \\
\hline \hline
\end{tabular}

We have just reported the parameter estimate $L 4$ since the other parameters $L 1, L 2, L 3$ of the seasonal intensity specification were not statistically significant. 
Table A.4.2

\begin{tabular}{|l|ll|ll|}
\hline & Sample & $01 / 97-12 / 98$ & Sample & $01 / 98-12 / 98$ \\
\hline Parameter & Coeff. & Std. Error & Coeff. & Std. Error \\
\hline$\phi$ & 0.28 & 0.028 & 0.22 & 0.026 \\
$M 1$ & 25.25 & 1.26 & 22.39 & 2.41 \\
$M 2$ & 20.40 & 2.66 & 19.46 & 4.59 \\
$M 3$ & 24.08 & 1.72 & 22.27 & 3.52 \\
$M 5$ & 22.22 & 2.61 & 23.38 & 3.81 \\
$M 6$ & 26.02 & 1.24 & 32.46 & 1.55 \\
$M 7$ & 22.87 & 1.81 & 22.73 & 2.45 \\
$M 8$ & 26.33 & 1.56 & 29.98 & 2.11 \\
$M 9$ & 25.39 & 2.10 & 28.96 & 2.72 \\
$M 10$ & 27.01 & 1.42 & 30.38 & 1.34 \\
$M 11$ & 24.93 & 2.10 & 22.75 & 3.52 \\
$M 12$ & 20.32 & 2.44 & 21.14 & 4.71 \\
$\sigma$ & 7.15 & 0.16 & 19.23 & 5.76 \\
$L 4$ & 0.17 & 0.04 & 7.61 & 0.23 \\
$\boldsymbol{\mu}_{J}^{\text {june }}$ & 38.33 & 50.00 & 0.17 & 0.06 \\
$\boldsymbol{\mu}_{J}^{\text {july,aug }}$ & 52.80 & 25.68 & 53.38 & 100.07 \\
$\sigma_{J}$ & 60.98 & 11.06 & 76.27 & 33.70 \\
\hline \hline
\end{tabular}


Figure A.4.1: One-month observed forward prices and estimated model.

January 1999 - March 2000

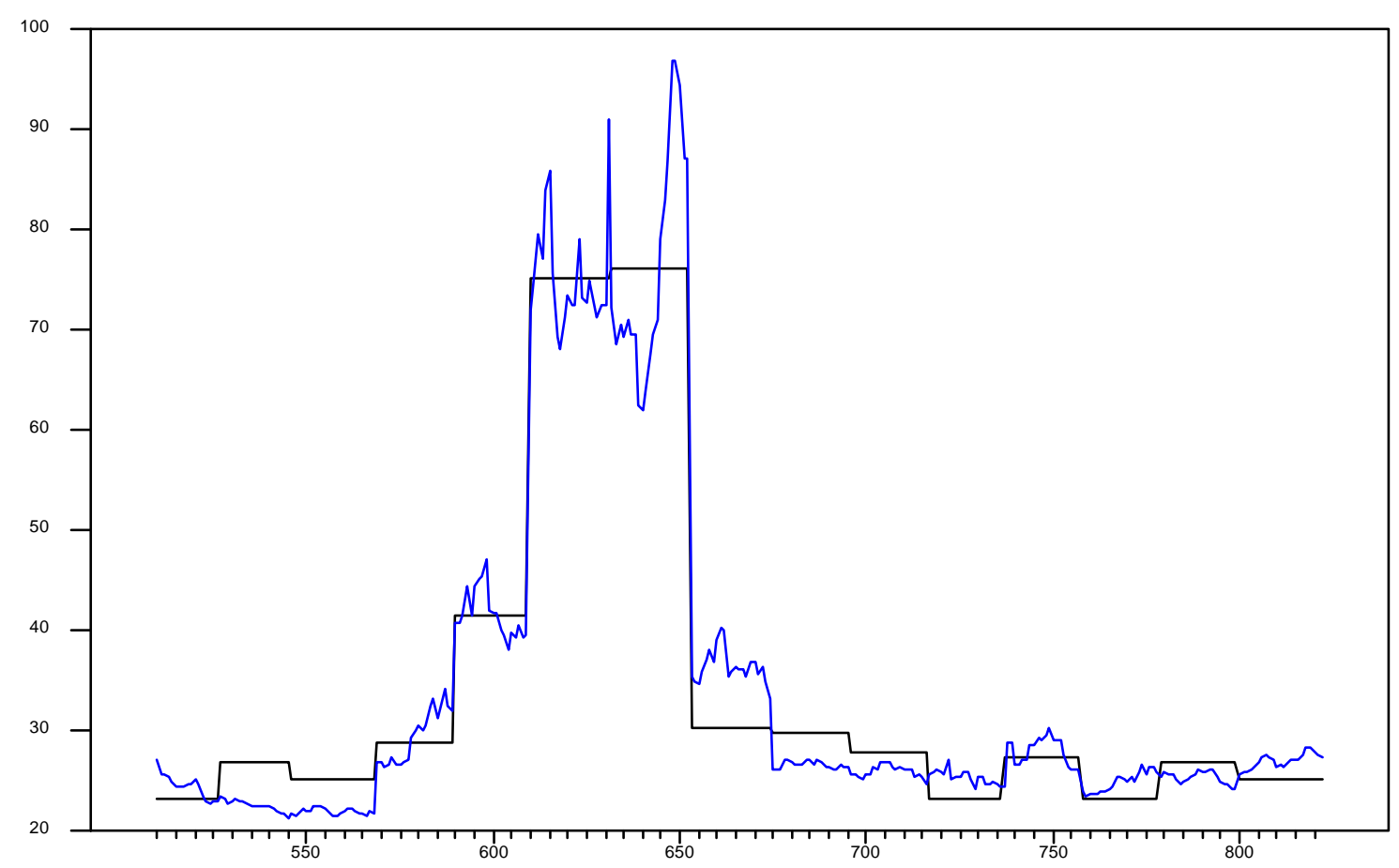


Figure A.4.2.: One-month forward contract, Model implied forward series (with $k$ $=0.7$, estimated from spot prices), Model implied forward prices with low meanreversion $(k=0.15)$

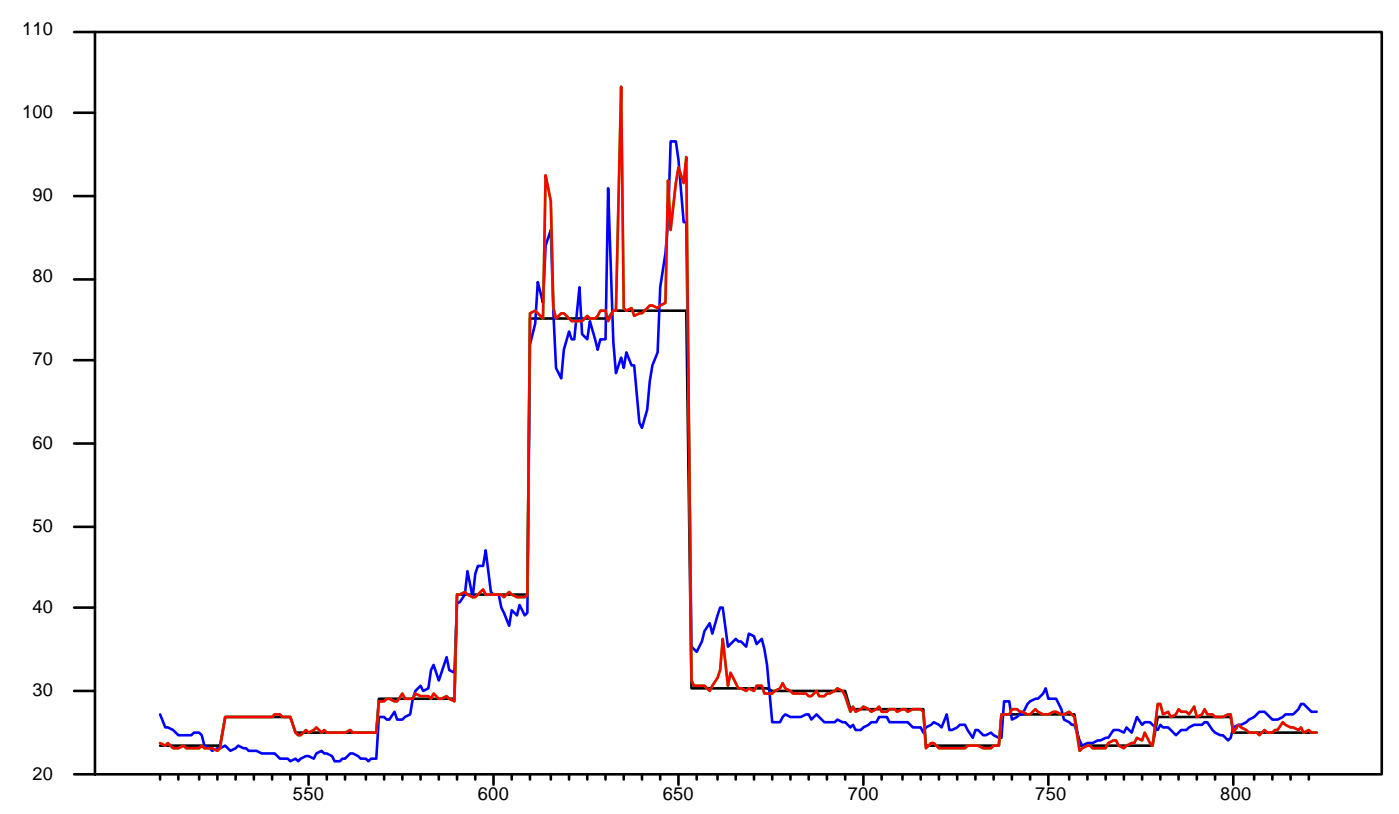




\section{REFERENCES}

Balduzzi, P., S.R. Das, S. Foresi and R.K. Sundaram, 1996. "A simple approach to threefactor affine term structure models", The Journal of Fixed Income, December.

Balduzzi, P., S.R. Das and S. Foresi, 1998. "The Central Tendency: a Second Factor in Bond Yields", Review of Economics and Statistics, 80, 62-72.

Balduzzi, P., S.R. Das, S. Foresi and R.K. Sundaram, 2000. "Stochastic Mean Models of the Term Structure of Interest Rates" in Advanced Fixed-Income Valuation Tools, Jegadeesh and Tuckman eds.

Bessembinder, H. and M.L. Lemmon, 2002. "Equilibrium Pricing and Optimal Hedging in Electricity Forward Markets”, Journal of Finance 57, 1347-82.

Das, S., 2002. "The surprise element: jumps in interest rates", Journal of Econometrics, vol. 106, pp. 27-65.

Deng, S., 2001. "Stochastic models of energy commodity prices and their applications: mean-reversion with jumps and spikes", UCEI, PWP-073.

Duffie, D., J. Pan and K. Singleton, 2000. "Transform analysis and asset pricing for affine jump-diffusions", Econometrica, vol. 68(6), 1343-1376.

Chacko G. and S. Das, 2002. "Pricing Interest rate derivatives: a general approach", Review of Financial Studies, 15(1), 195-241.

Cipra, T. and Romera, R. (1991), "Robust Kalman Filter and its applications in Time Series Analysis", Kybernetika, 27(6), 481-494.

Escribano, A., J.I. Peña and P. Villaplana, 2002. "Modeling electricity prices: international evidence", Universidad Carlos III, working paper 02-27.

Heston, S. (1993). “A Closed-Form Solution of Options with Stochastic Volatility with Applications to Bond and Currency Options", Review of Financial Studies, 6, 327-343.

Geman, H. and Vasicek, O. (2001), "Forwards and Futures contracts on non-storable commodities: the case of electricity", Risk, August.

Geman, H. and A. Roncoroni (2003). “A Family of Reduced-Form Models for Electricity Prices", working paper ESSEC.

Hirshleifer, D., 1990. "Hedging Pressure and Futures Price Movements in a General Equilibrium Model", Econometrica, 58 (2), pp. 411-428.

Jegadeesh N. and G.G. Pennacchi, 1996. "The behavior of interest rates implied by the term structure of eurodollar futures", Journal of Money, Credit and Banking, vol. 28(3), 427-446. 
Knittel, C.R. and M. Roberts, 2001. "An empirical examination of deregulated electricity prices", UCEI, PWP-087.

Longstaff, F., and A. Wang, 2002. "Electricity Forward Prices: a high-frequency empirical analysis", Working Paper, UCLA.

Lucia, J. and E. Schwartz, 2001. "Electricity prices and power derivatives. Evidence from Nordic Power Exchange", Review of Derivatives Research, vol. 5 (1), 5-50.

Pan, J., 2002 "The jump-risk premia implicit in options: evidence from an integrated timeseries study", Journal of Financial Economics, vol.63, 3-50.

Pirrong, C. and Jermakyan, M. (2000). "The Price of Power: the Valuation of Power and Weather Derivatives", working Paper, Olin School of Business, Washington University.

Schwartz, E., 1997. "The stochastic behavior of commodity prices: implications for valuations and hedging”, Journal of Finance, vol. 52(3), 923-973.

Schwartz, E. and J.E. Smith, 2000. "Short-term variations and long-term dynamics in commodity prices", Management Science, 46 (7), 893-911.

Singleton, K., 2001. "Estimation of Affine Asset Pricing Models using the Empirical Characteristic Function”, Journal of Econometrics, 102, 111-141. 